\title{
Influence of Cold Rolling Temperature Rise on the Young's Modulus of Commercial Fe-3\%Si Steel
}

\section{Y.N. Loginov ${ }^{1,2}$, S.l. Stepanov ${ }^{1}$, M.P. Puzanov¹, and A.G. Nezhdanov ${ }^{1}$}

${ }^{1}$ Ural Federal University named after the first President of Russia B.N. Yeltsin, 19 Mira str., Ekaterinburg, 620002, Russia

${ }^{2}$ M.N. Miheev Institute of Metal Physics of Ural Branch of Russian Academy of Sciences, $18 \mathrm{~S}$. Kovalevskaya Street, Yekaterinburg, Russian Federation, 620137

\section{Abstract}

Dynamic mechanical analysis was performed on the sheets of commercial grainoriented steel $\mathrm{Fe}-3 \% \mathrm{Si}$ in annealed and cold-rolled conditions. The Young's modulus was measured according to the 3-point bending scheme in the temperature range of $20 \ldots 550{ }^{\circ} \mathrm{C}$. The difference between the values of the elastic properties in the rolling direction and transverse directions were explained with the peculiarities of the

Corresponding Author:

Y.N. Loginov

j.n.loginov@urfu.ru

Received: 25 February 2019

Accepted: 9 April 2019

Published: 15 April 2019

Publishing services provided by Knowledge E

(c) Y.N. Loginov et al. This article is distributed under the terms of the Creative Commons

Attribution License, which permits unrestricted use and redistribution provided that the original author and source are credited.

Selection and Peer-review under the responsibility of The Ural school-seminar of metal scientists-young researchers Conference Committee.

\section{G OPEN ACCESS} structural and textural states. Two extreme points in the Young's modulus temperature dependence are explained with the oxidation process, which occurs during heating of the samples. The obtained data can be employed to refine the simulation of the stress-strain state in cold rolling of commercial Fe-3\%Si by the finite element method.

Keywords: Grain-oriented steel, cold rolling, storage modulus, dynamic mechanical analysis, anisotropy, crystallographic texture

\section{Introduction}

Commercial grain-oriented (CGO) steel is utilized for the manufacturing of transformer cores and electrical machines due to its high magnetic properties [1-4]. CGO is characterized by a significant anisotropy of magnetic characteristics. The anisotropy is employed for creating the electromagnetic fields in the certain direction. The unique magnetic properties caused by the Goss $\{110\}<001>$ texture after secondary recrystallization occur along the rolling direction.

The CGO steel is produced in the form of thin sheets with the cold rolling (CR) as the final stage of processing. Note, that the parameters of the CR define the magnitude of magnetic properties [5]. However, considerably less attention is paid to the investigation of mechanical properties anisotropy, which results from the deformation processing and heat treatment [6]. This question becomes relevant for the precise determination 
of energy-power parameters of the $\mathrm{CR}$ or when it is necessary to estimate the stressstrain state, which occur during metal forming. At present, such calculations are carried out using the finite element method, for which the statement of the problem requires the elastic properties to be defined correctly. The CR is accompanied by a significant heating on the contact surface with the rolls despite the use of powerful cooling systems in manufacturing of the grain-oriented steel. This heating is accounted for the conversion of deformation energy and friction into heat [7] which results from by the high strength properties of steel [8].

The purpose of the study is to determine the elastic properties of the commercial Fe$3 \% \mathrm{Si}$ steel in the temperature range from room temperature up to $550^{\circ} \mathrm{C}$ which may be reached during cold rolling.

\section{Material and Methods}

Two types of COG steel sheets were investigated. The first was subjected to the first $\mathrm{CR}$ from 2.5 to $0.7 \mathrm{~mm}$ followed by a recrystallization-decarburizing annealing in the humidified nitrogen protective atmosphere $\left(95 \% \mathrm{~N}_{2}+5 \% \mathrm{H}_{2}\right)[9,10]$; 2) after second $\mathrm{CR}$ on the quarto reversing mill to a thickness of $0.26 \mathrm{~mm}$. Reduction area (RA) at the first and second CR were 72 and 63\% respectively. A water-oil emulsion was used as a metalworking fluid during the rolling. Samples were sectioned from the sheets in the rolling direction (RD) and in the transverse direction (TD). Then the samples were degreased using an aqueous-alkaline solution and alcohol.

The storage modulus analogue of the Young's modulus of the steel was investigated using dynamic mechanical analysis (DMA) on the DMA 242C NETZSCH. The DMA is based on measuring the response of a sample to an oscillating load that is periodically varied according to a given law.

The DMA allows for the identification of structural effects that occur during heating of the material [11]. In combination with the metallographic analysis, it enables to explain the origin of these effects. The samples were examined according to the three-point bending under a load of $9 \mathrm{~N}$ in an inert atmosphere of argon. The sample (1) is placed on the supports (2) and loaded by the die placed in the center of length of the sample (3) according to the arrow direction (Fig. 1).

The samples with a length of $20 \mathrm{~mm}$ and a width of $4 \mathrm{~mm}$ were heated to $550{ }^{\circ} \mathrm{C}$ at a rate of $20^{\circ} \mathrm{C} / \mathrm{min}$. The loading frequency was $1 \mathrm{~Hz}$. 


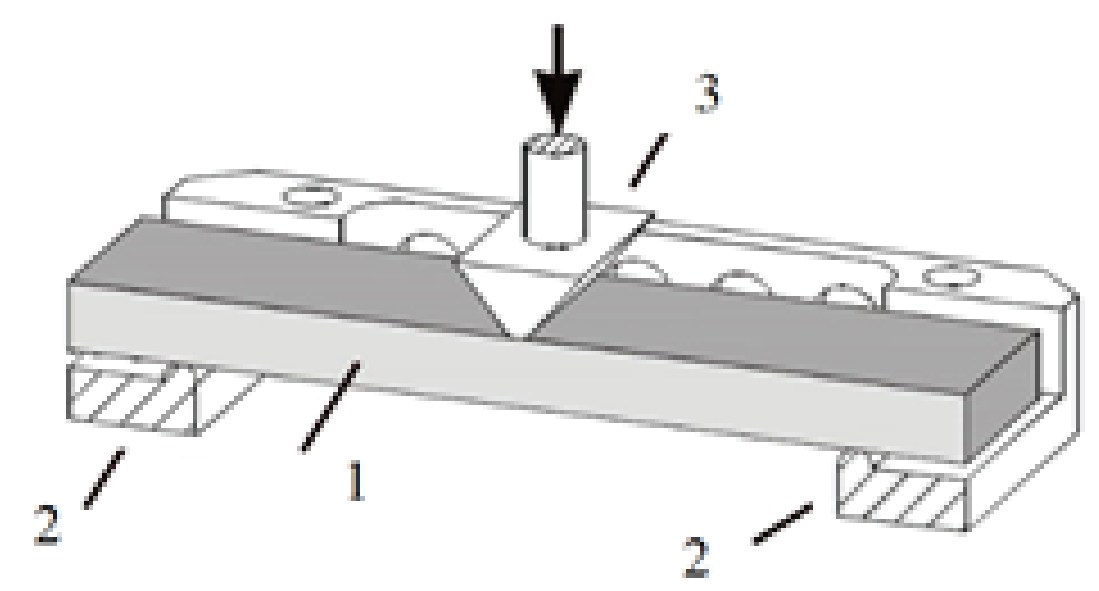

Figure 1: DMA 3-point bending loading scheme: 1 - sample; 2 - stationary clamps; 3 - die.

The quantification of the storage modulus of elasticity $E$ is based on the following relationship:

$$
E=\frac{l^{3}}{4 \cdot b \cdot h^{3}} \cdot \frac{F}{a}
$$

where $I$ - the distance between the clamps; $F$ - dynamic loading; $h$ - sample height; $a$ - dynamic displacement; $b$ - width of the sample.

The stress state during loading changes from the stretching of layers on the top surface perpendicular to the loading direction through the neutral fibers in the center of the height of the sample to the compression on the bottom surface. Thus, for metals the storage modulus is almost equivalent to the modulus of normal elasticity known as the Young's modulus. However, it is measured mainly for the surface layers of the material which are perpendicular to the direction of loading.

\section{Results and Discussion}

The Young's modulus values measured at the room temperature lie in the range of 170...240 GPa for both structural conditions (Fig. 2, Table 1). This corresponds to the conventional non-textured state of the material (200...214 GPa) or to the preferred orientation of deformation cube $\{001\}<110>$, for which the Young's modulus is $210 \mathrm{GPa}$ in both the RD and TD.

The orientation dependence of storage modulus (in various structural states of the material and at different temperatures) is mainly defined by the development of crystallographic texture (Table 1). For the cold-rolled Fe-3\%Si sheet, the main texture components of the surface layer are: $\{111\}<112>,\{111\}<110>,\{112\}<110>-$ namely, two preferred orientations for each of the above set [11]. Thus, the magnitude of the modulus 
of 169 GPa measured along the RD is mainly determined by the set of crystallographic directions $<112>$ and $\langle 110\rangle$. The rotation of the sample by $90^{\circ}$ leads to a change in the textural components combination: $\{111\}<110>,\{111\}<112>,\{112\}<111>$. Thus, the storage modulus is $212 \mathrm{GPa}$ along the set of corresponding axes $<110\rangle,<112>$ and $<111>$. The latter is characterized by the maximum of the Young's modulus according to [6]. The above effect can be enhanced if central layers of the material are involved in the measurement of the modulus. The main texture components of the central layers in $\mathrm{RD}$ are $\{001\}<110\rangle,\{112\}<110\rangle[13]$ and the texture is distributed by the $\{001\}<110\rangle$, $\{112\}<111>$ orientations in TD.

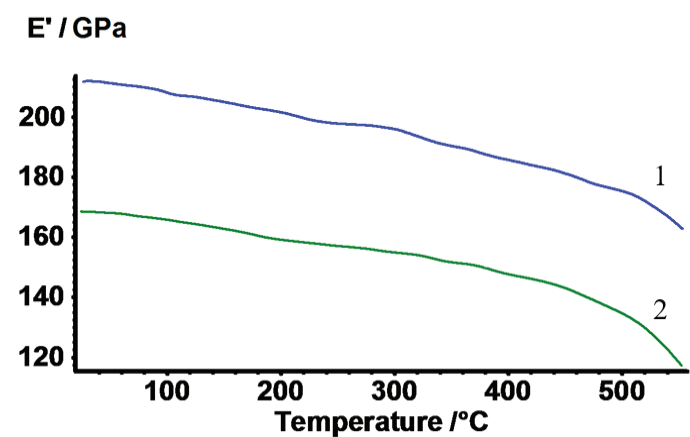

a

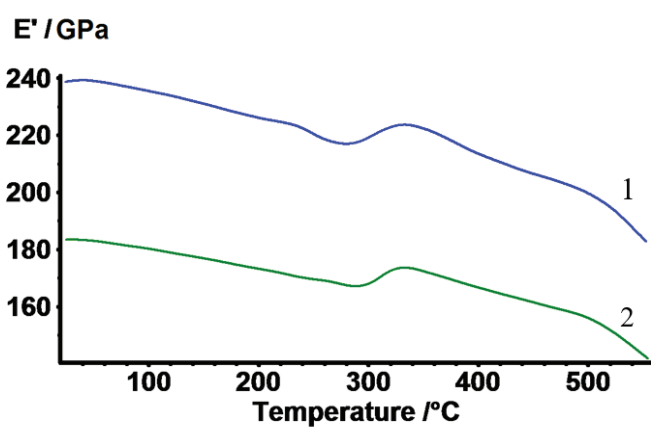

b

Figure 2: Storage modulus as a function of temperature for commercial cold-rolled Fe-3\%Si steel sheets studied by DMA in TD (1) and RD (2): (a) - RA 63\% (sheet thickness of 0.26 mm); (b) - CR on RA of $72 \%$ (sheet thickness of $0.7 \mathrm{~mm}$ ) followed by the recrystallization-decarburizing annealing.

Although the recrystallization does not considerably change the texture type [12, 13], it significantly weakens the severity of the main components due to the strengthening of the weaker components ("textureless component" - $\{h \mathrm{hl}\}<\mathrm{uvw}>$ ). The storage modulus increase both in RD and in TD, apparently, due to the enhancement of the "textureless component". However, the ratio between the modulus in the RD and in TD maintains 1.3 .

A general decrease in the storage modulus by $24 \%$ is observed for the samples heated to $550{ }^{\circ} \mathrm{C}$, regardless of their structural-textural state. The storage modulus decrease almost linearly when heating up to approximately $500{ }^{\circ} \mathrm{C}$. Further heating decrease the modulus noticeably more intensive. The initial decrease in the modulus is apparently accounted for a weakening of the interatomic bonds in the Fe-3\% Si solid solution due to the intensification of atomic oscillations. The change of the modulus slope in the temperature range of $500 . .5500^{\circ} \mathrm{C}$ is presumably caused by the weakening of the contribution of the interatomic magnetic interaction to the cohesive energy.

Two local extremes occur in the DMA curves for the sheet with a thickness of $0.7 \mathrm{~mm}$ in a recrystallized state. The first is a minimum at $280^{\circ} \mathrm{C}$ and the second is a maximum at 


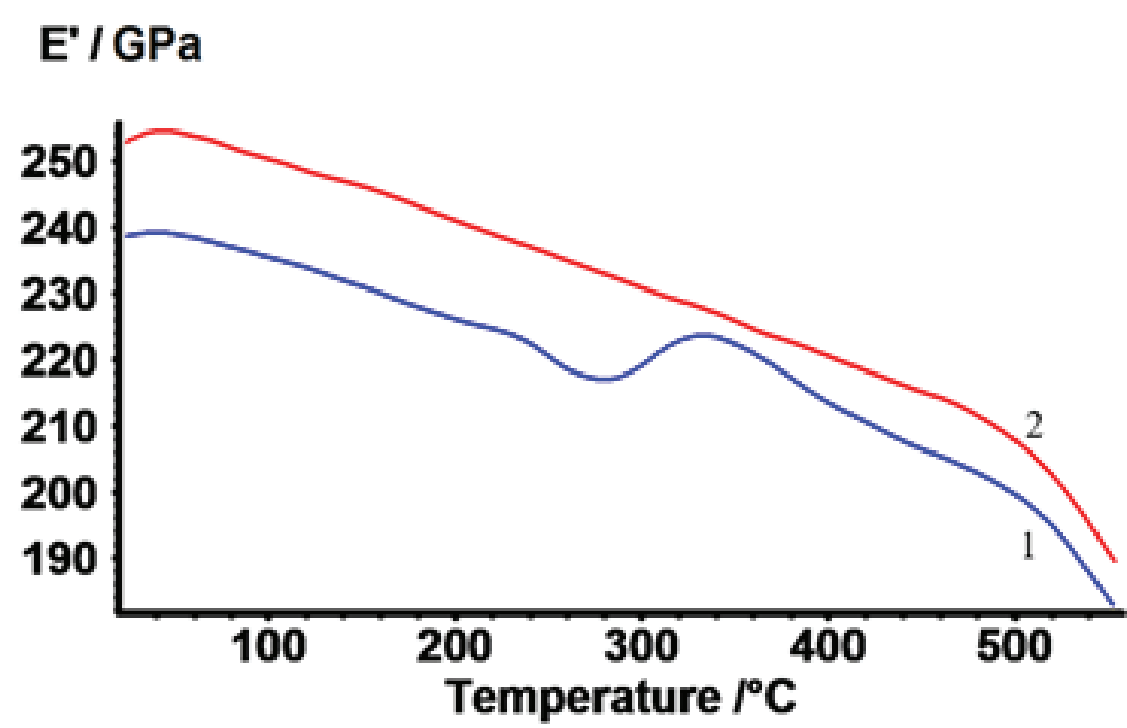

Figure 3: Storage modulus as a function of temperature in TD for cold-rolled Fe-3\%Si and annealed sheets of $0.7 \mathrm{~mm}$ thickness: 1 - the first heating, 2 - reheating.

$340{ }^{\circ} \mathrm{C}$ (Fig. 2, b). Note, that the samples were covered with the oxide layer despite the inert atmosphere employed during heating. However, both extremes disappear in the modulus temperature dependence in the curves for reheating of the oxidized samples.

The extremes in the region near $300^{\circ} \mathrm{C}$ are absent for $\mathrm{CR}$ specimens with a thickness of $0.26 \mathrm{~mm}$ (Fig. 3). In this case, the formation of an oxidized layer on the surface of the samples is not observed.

According to $[9,10,14]$ the sheets of CGO steel are characterized by a thin surface continuous layer with the thickness of 3-6 $\mu \mathrm{m}$ after recrystallization-decarburization annealing. This layer consists of Fe-based solid solution depleted by silicon (up to $1 \mathrm{wt} . \%$ ) and of the oxide precipitates, which are predominantly $\mathrm{SiO}_{2}$. The study [10] shows that, $\mathrm{H}_{2} \mathrm{O}$ vapor oxidize the $\mathrm{Fe}-3 \% \mathrm{Si}$ steel over silicon during the decarburization annealing in the temperature range of $790 \ldots 860^{\circ} \mathrm{C}$. Further reheating results in the formation of $\mathrm{FeO}$ in this layer even for a small amount of oxygen in the atmosphere. Thus, the formation of a solid, composite $\left(\mathrm{SiO}_{2}\right.$ in $\left.\mathrm{FeO}\right)$, completely oxide layer is the reason for the rise of the elastic modulus in case of $0.7 \mathrm{~mm}$ sheets.

The sheets with a thickness of $0.26 \mathrm{~mm}$ were oxidized by Fe during the CR already. The temperature in the deformation zone can reach $350 . .400{ }^{\circ} \mathrm{C}$ according to the estimates. The volume concentration of the oxygen increase from $270 . .290$ to $320 . . .340$ ppm for these sheets during CR. Thus, the DMA was carried out in the presence of an oxide film on the surface of the samples, which on the one hand protected the surface from further oxidation and on the other led to the overestimated values of the storage modulus compared to the unoxidized metal. 
TABLE 1: Elastic moduli for Fe-3\%Si steel at $20^{\circ} \mathrm{C}$ for various conditions of measurement.

Conditions of investigation
Single crystal Fe-3\%Si
Single crystal Fe-3\%Si
Single crystal Fe-3\%Si
Isotropic steel Fe-3\%Si
CR $\varepsilon=63 \%$ in $\mathrm{RD}$
$\mathrm{CR} \varepsilon=63 \%$ in TD
CR( $\varepsilon=72 \%)+$ recrystallization
annealing in RD
CR( $\varepsilon=72 \%)+$ recrystallization
annealing in TD

Preferred orientation
$<100>$
$<110>$
$<111>$
$\{$ hkl $\}<\mathrm{uvw}>$
Surface: $\{111\}<112>,\{111\}<110>$,
$\{112\}<110>,\{\mathrm{hkl}\}<\mathrm{uvw}>$
Center: $\{001\}<110>,\{112\}<110>$
Surface: $\{111\}<110>,\{111\}<112>$,
$\{112\}<111>$. $\{\mathrm{hkl}\}<\mathrm{uvw}>$
Center: $\{001\}<110>,\{112\}<111>$.
Surface: $\{111\}<112>,\{111\}<110>$,
$\{112\}<110>,\{\mathrm{hkl}\}<\mathrm{uvw}>$
Center: $\{001\}<110>,\{112\}<110>$,
$\{\mathrm{hkl}\}<\mathrm{uvw}>$
Surface: $\{111\}<110>,\{111\}<112>$,
$\{112\}<111>,\{\mathrm{hkl}\}<\mathrm{uvw}>$
Center: $\{001\}<110>,\{112\}<111>$,
$\{\mathrm{hkl}\}<\mathrm{uvw}>$

\begin{tabular}{|c|c|}
\hline $\mathrm{E},[\mathrm{GPa}]$ & Source \\
\hline 127 & {$[6]$} \\
\hline 210 & \\
\hline 270 & \\
\hline $200 \ldots 214$ & \\
\hline 169 & Present study \\
\hline 212 & \\
\hline & \\
\hline 184 & \\
\hline
\end{tabular}

\section{Conclusions}

The dynamic mechanical analysis revealed that the Young's modulus of commercial Fe$3 \% \mathrm{Si}$ steel can take values from 150 to $250 \mathrm{GPa}$ in the temperature range of $20 \ldots 400^{\circ} \mathrm{C}$ depending on the direction of measurement and the condition of the rolled surface. The modulus of elasticity measured in transverse direction of cold-rolled OCG steel sheet may exceed the modulus of elasticity in rolling direction by 1.3 times, which is explained with the crystallographic texture of the material. The more precise values of the elastic modulus were calculated, which can be utilized for FEA simulation of the stress-strain state in cold rolling.

\section{Acknowledgments}

The work financially supported by the RF Government decree № 211 (contract № 02.A03.21.0006).

\section{References}

[1] S. Fortunati, G.C. Abbruzzese, S. Cicalè, New Frontiers for Grain Oriented Electrical Steels: Products and Technologies, 7th International Conference on Magnetism and 
Metallurgy WMM16, Rome, June 13th-15th, (2016).

[2] M.L. Lobanov, A.A. Redikultsev, G.M. Rusakov, Electrotechnical anisotropic steel. Part I. History of development, Metal Science and Heat Treatment, 53, No. 7-8 (2011) 326332.

[3] M.L. Lobanov, A.A. Redikultsev, G.M. Rusakov, Electrotechnical anisotropic steel. Part II. State -of-the-art, Metal Science and Heat Treatment, 53, No. 7-8 (2011) 355-359.

[4] Z. Xia, Y. Kang, Q. Wang, Developments in the production of grain-oriented electrical steel, Journal of Magnetism and Magnetic Materials, 254-255 (2008) 307-314.

[5] A.G. Uritskii, S.V. Smirnov, A.A. Redikultsev, M.L. Lobanov, G.M. Rusakov, Structure and texture formation over the width of ferritic-steel strip in hot rolling, Steel in Translation, 44, No. 10 (2015) 723-726.

[6] M.L. Lobanov, A.A. Redikul'tsev, G.M. Rusakov, S.V. Danilov, Interrelation between the orientations of deformation and recrystallization in hot rolling of anisotropic electrical steel, Metal Science and Heat Treatment, 57, No. 7-8 (2015) 492-497.

[7] Y.N. Loginov, M.P. Puzanov, A.G. Uritskii, Reducing the edge deformation of thin electrical steel sheet, Steel in Translation, 47(4), (2017) 267-273.

[8] V.D. Solovei, Yu.N. Loginov, M.P. Puzanov, Evaluating the flow stress of electrical steel under cold rolling in terms of the strain-rate hardening effect, AIP Conference Proceedings, 1785, November 18th, (2016) 040075.

[9] M.L. Lobanov, A.S. Yurovskikh, Thermochemical treatment of anisotropic electrical steel, Metal Science and Heat Treatment, 58, No. 11-12 (2017) 667-673.

[10] M.L. Lobanov, A.I. Gomzikov, S.V. Akulov, A.I. Pyatygin, Decarburizing annealing of technical alloy Fe - 3 \% Si, Metal Science and Heat Treatment, 47, No. 9-10 (2005) 478-483.

[11] Albert Fabregat-Sanjuan, Francesc Gispert-Guirado, Francesc Ferrando, Silvia De la Flor, Identifying the effects of heat treatment temperatures on the Ti50Ni45Cu5 alloy using dynamic mechanical analysis combined with microstructural analysis, Materials Science and Engineering: A, 712, January 17th (2018), pp. 281-291.

[12] M.L. Lobanov, A.A. Redikultsev, G.M. Rusakov, A.S. Belyaevskikh, Influence of Pass Aging in Cold Rolling on the Structure and Properties of Fe-3\% Si Steel, Steel in Translation, 45, No. 7 (2015) 494-498.

[13] H. Cheng-Xu, Y. Fu-Yao, M. Guang, Ch. Xin, M. Li, $\{411\}<148>$ Texture in Thin-Gauge Grain-Oriented Silicon Steel, Acta Metall. Sin. (Engl. Lett.), (2016) DOI 10.1007/s40195016-0419-9. 
[14] S. Jung, M.S. Kwon, J. Park, et. al., A TEM Study of Oxide Layers Formed during Decarburization Annealing of Electrical Steel, ISIJ International, 51 (2011), pp. 11631168. 